\title{
In-vitro Evaluation of Actinobacteria for its Potential in Bio-control of Fungal Plant Pathogens
}

\author{
Zothanpuia*1 $^{* 1}$ W. Carrie ${ }^{2}$, V.V. Leo ${ }^{3}$, A.K. Passari ${ }^{4}$ R. Lalmuanpuii ${ }^{5}$ and B.P. Singh ${ }^{6}$ \\ ${ }^{1}$ Department of Biotechnology, Pachhunga University College, \\ College Veng, Aizawl, Mizoram-796005 \\ 2,3,4,6 Department of Biotechnology, Mizoram University, Tanhril, Mizoram-796004 \\ ${ }^{5}$ Department of Botany, Mizoram University, Tanhril, Mizoram-796004 \\ E-mail: *jpahnamte6@gmail.com
}

\begin{abstract}
Infections caused by fungal plant pathogens are recently recognized as a threat to food security worldwide and its control strategies need to be taken care where naturally synthesized fungicides such as those obtained from actinobacteria are becoming an area of great interest. A total of 68 isolates of actinobacteria were evaluated for their antagonistic potential against four fungal plant pathogens viz., Fusarium oxysporum CABI-293942, Fusarium udum MTCC-2755, Fusarium proliferatum MTCC-286 and Fusarium graminearum MTCC-1893 by dual culture in-vitro assay. It was found that $83.8 \%$ of the isolates showed inhibitory activity against at least one of the tested plant pathogens with the percentage of inhibition ranging from 20-87.2. Thirteen Streptomyces isolates and one Nocardiposis isolate exhibited inhibition activity against all the tested pathogens. Overall, this study gives a basic understanding of the potential aspect of freshwater sediments derived actinobacteria against fungal phytopathogens.
\end{abstract}

Keywords: Anti-fungal, Phyto-pathogens, Nocardiopsis, Streptomyces

\section{INTRODUCTION}

Fungal diseases are one of the most common problems to certain crops upon which humanity depends (Godfray et al. 2016) and compounds derived from actinobacteria represent a promising agent to tackle the problems (Wang et al. 2018; Qi et al. 2019). Actinobacteria are Gram +ve bacteria, ubiquitous in nature, typically soil dwellers (Goodfellow and Williams 1983), found commonly in freshwater ecosystems (Sibanda et al. 2010). Various habitats have been explored in search of actinobacteria and several useful compounds have been expansively reported from different ecosystems (Maldonado et al. 2005; Passari et al. 2015). However, there has been a significant decline in the rate of discovery of novel actinobacteria in recent years and there has been increasing isolation of known organisms besides re-isolation of known compounds (Zotchev 2012).

Mizoram, Northeast India, is a large bio-prospecting area identified as the Indo-Burma mega-biodiversity hotspot by Conservation International (Myers et al. 2000). All the lakes and rivers of Mizoramare freshwater (Zothanpuia etal. 2015).
Few actinobacteriological research has been reported from Mizoram such as freshwater sediments derived actinobacteria for its potential as antimicrobial agent and secondary metabolites producer (Zothanpuia et al. 2018), endophytic actinobacteria as biologically active compounds and phytohormone producers (Passari et al. 2015) and plants growth promoters (Passari et al. 2016). Investigation on the antifungal potential of actinobacteria from freshwater sediments may give a basic understanding and will provide baseline data for further studies that are significant for biotechnological exploitation especially in the management of food security.

\section{MATERIALS AND METHODS}

\section{ISOLATION AND CHARACTERIZATION OF ACTINOBACTERIA}

Serial dilution and spread plate technique were used for the isolation actionobacteria from freshwater sediments of Tlawng river, Tuirial river and Tamdil lake (Yuan et al. 2014; 
Zothanpuia et al. 2018). Seven different nutritional media were used for the isolation such as starch-casein agar (SCA), yeast-extract malt-extract agar (ISP2), Actinomycetesisolation agar (AIA), Streptomyces agar (SA), glycerolasparagine agar (ISP5), tyrosine-agar medium (ISP7), and tap-water yeast-extract agar (TW-YE), the isolated organisms were characterized as exactly reported in the previous studies (Zothanpuia et al. 2018).

\section{SCREENING FOR ANTIFUNGAL ACTIVITY}

The actinobacterial isolates were evaluated for their antagonistic potential against four fungal phytopathogens collected from microbial type culture collection (MTCC), Chandigarh, India viz., Fusarium oxysporum CABI-293942, Fusarium udum MTCC-2755, Fusarium proliferatum MTCC-286 and Fusarium graminearum MTCC-1893 by dual culture in-vitro assay (Khamna et al. 2008). Colony growth inhibition (\%) was calculated by using the formula: $\mathrm{C}-\mathrm{T} / \mathrm{C} \times 100$, where $\mathrm{C}$ is the colony growth of the fungal pathogen in control, and $\mathrm{T}$ is the colony growth of the fungal pathogen in presence of actinobacteria. All isolates were tested in triplicate and mean values were calculated.

\section{RESULTS AND DISCUSSION}

Actinobacteria remains an important source of important biologically active compounds effective against certain plant and animal diseases (Goodfellow and Fiedler 2010; Yuan etal. 2014). The present investigation isolated 68 actinobacteria from freshwater sediments of Mizoram, Northeast India; 30 isolates from Tamdil Lake, 19 from Tlawng River, 19 from Tuirial River, and were earlier discussed in the previous article (Figure 1) (Zothanpuia et al. 2018).

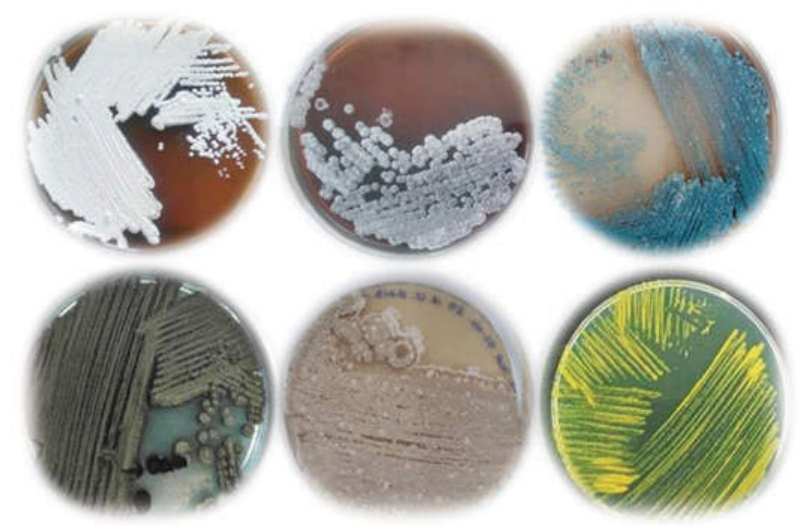

Fig. 1: Morphological Features of Actinobacteria Isolated from Freshwater Sediments
Streptomyces represent the most dominantgenus among the isolated organisms (72\%), followed by Nocardiopsis, Saccharopolyspora, Rhodococcus, Prauserella, Amycolatopsis, Promicromonospora, Kocuria and Micrococcus, the 16S rRNA gene sequences of all the isolates were deposited in NCBI GenBank database and accession numbers were given as cited (Zothanpuia et al. 2018). This study revealed that Lakes and rivers are important reservoirs of actinobacteria (Leiva et al., 2004).

Aactinobacteria represents one of the most potential candidates to tackle the problems associated with the fungal plant pathogens that were largely reported as a potent biocontrol agent (Nafis et al. 2018; Qi et al. 2019). Diseases and the problems caused especially by the genus Fusarium were reported worldwide (Lamprecht et al. 2011) which include wilting, chlorosis, necrosis, premature leaf fall, stunting, etc. The antifungal activity was checked to understand the inhibition ability of the isolated actinobacteria against four fungal pathogens by dual culture in-vitro assay, which is a method widely used for preliminary screening (Zothanpuia et al. 2018a). The phytopathogens include $F$ udum, $F$ oxysporum, F. graminearum and $F$. proliferatum which were reported as pathogens maintained in the microbial type culture collection. From a total of 68 actinobacterial isolates tested, $83.8 \%(n=57)$ of the isolates showed inhibition activity against at least one of the tested pathogens (Table 1). This justified the antifungal potential of actinobacteria from freshwater sediments supported by the findings of Rifaat (2003) that demonstrated the anti-mycotic activity of 114 freshwater actinobacteria from Nile River. 14 isolates viz. Streptomyces cyaneofuscatus DST15, Streptomyces sp. DST16, Streptomyces sp. DST25, Saccharopolyspora sp. DST31, Streptomyces griseoplanus DST53, Streptomyces sp. DST54, Streptomyces cyaneofuscatus DST64, Streptomyces albidoflavus DST71, Streptomyces sp. DST86, Streptomyces albidoflavus DST102, Streptomyces sp. DST104, Nocardiopsis sp. DST105, Streptomyces sp. DST116 and Streptomyces sp. DST119 showed activity against all the tested four Fusarium pathogens. Maximum inhibitory activity of the actinobacterial isolates was found against $F$ graminearum (46.4\%) [Figure 2 (I)], followed by F. proliferatum $(30.4 \%)$ [Figure 2 (II)], F. oxysporum (29.5\%) [(Figure 2 (III)] and Fusarium udum (26.9\%) [(Figure 2 (IV)] with percentage of inhibition ranging from 20-87.2. It was earlier reported the antifungal potential of two actinobacterial isolates Streptomyces sp. DST23 and Streptomyces parvus DST24 against F. oxysporum, F. proliferatum, and F. oxy. ciceri from freshwater Tuichang river (Zothanpuia et al. 2015) 
which was in accordance with the reports of Streptomyces from Krishna river showing antibacterial and antifungal activity (Ellaiah et al. 2002). A similar investigation was also executed in Lake Baikal, the largest freshwater lake worldwide that described more than $70 \%$ of the isolates having an antifungal activity (Protasov et al. 2017). Among all the isolated organisms, Streptomyces sp. DST25 showed the maximum percentage of inhibition against Fusarium Udum $(87.20 \%)$ which justified the potential of Actinobacteria especially Streptomyces in fighting the diseases caused by fungal pathogens supported by the findings of Nafis et al. (2018) and Qi et al. (2019). Streptomyces are among the largest contributors of antibiotics in the microbial world, widely distributed in soil and also colonize water and other natural environments (Goodfellow and Fiedler 2010). Most research including the present study is an early experimental stage but revealed the ability of Streptomyces in the control of fungal plant pathogens which was also supported by the review of Bubici (2018). Upon further investigations on the lead compounds, isolation, identification, and bioformulation of freshwater sediments derived actinobacteria may help in the development of control strategies of fungal plant diseases which remains a great concern worldwide.

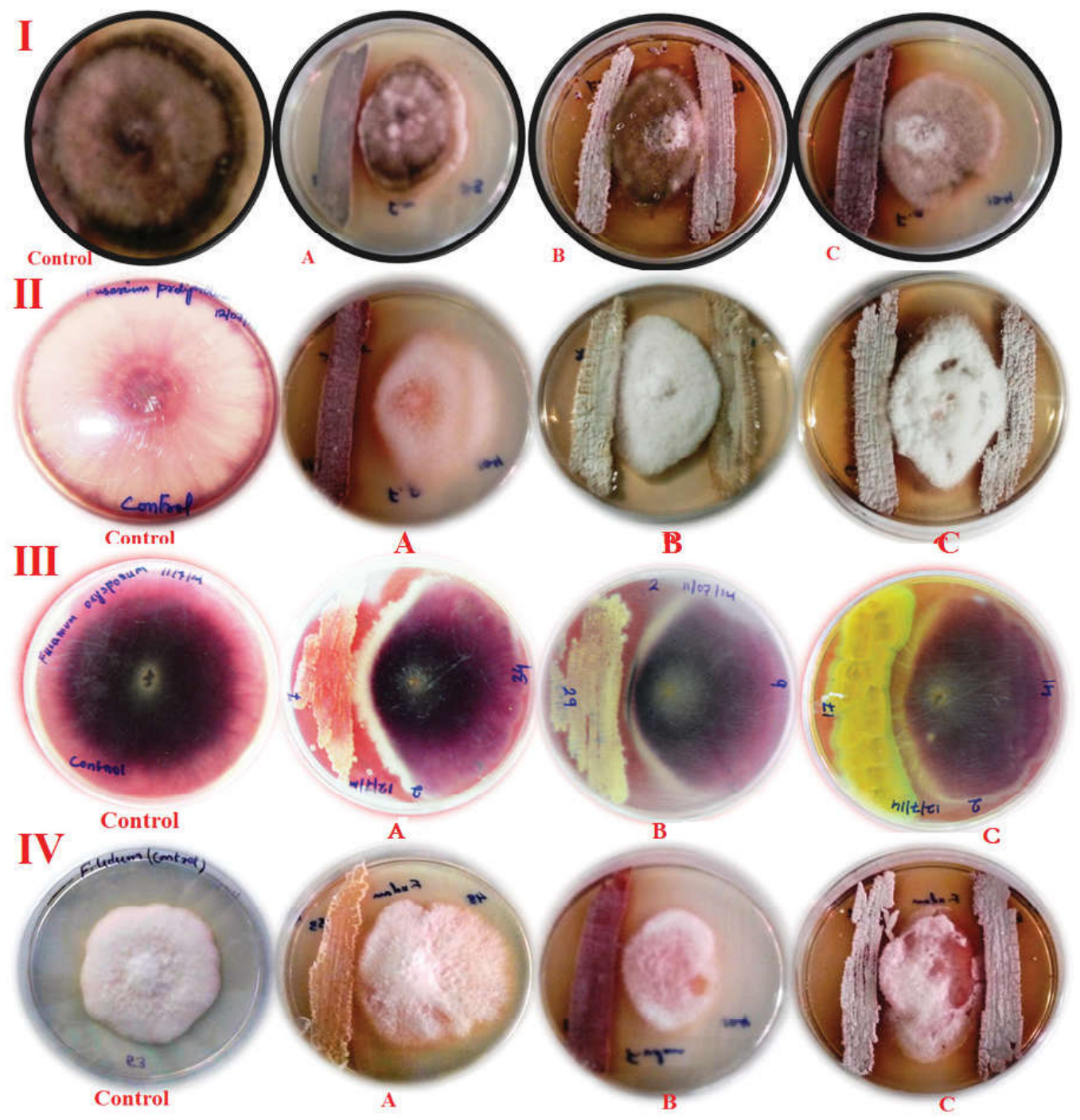

Fig. 2: (I) Antifungal Activity of Actinobacterial Isolates Against F graminearum (II) F. proliferatum (III) F. oxysporum and (IV) F. udum. Control-Fungal Pathogens without Actinobacteria and A, B and C Denotes the Dual Culture; Growth of Pathogens Inhibited by Actinobacteria 


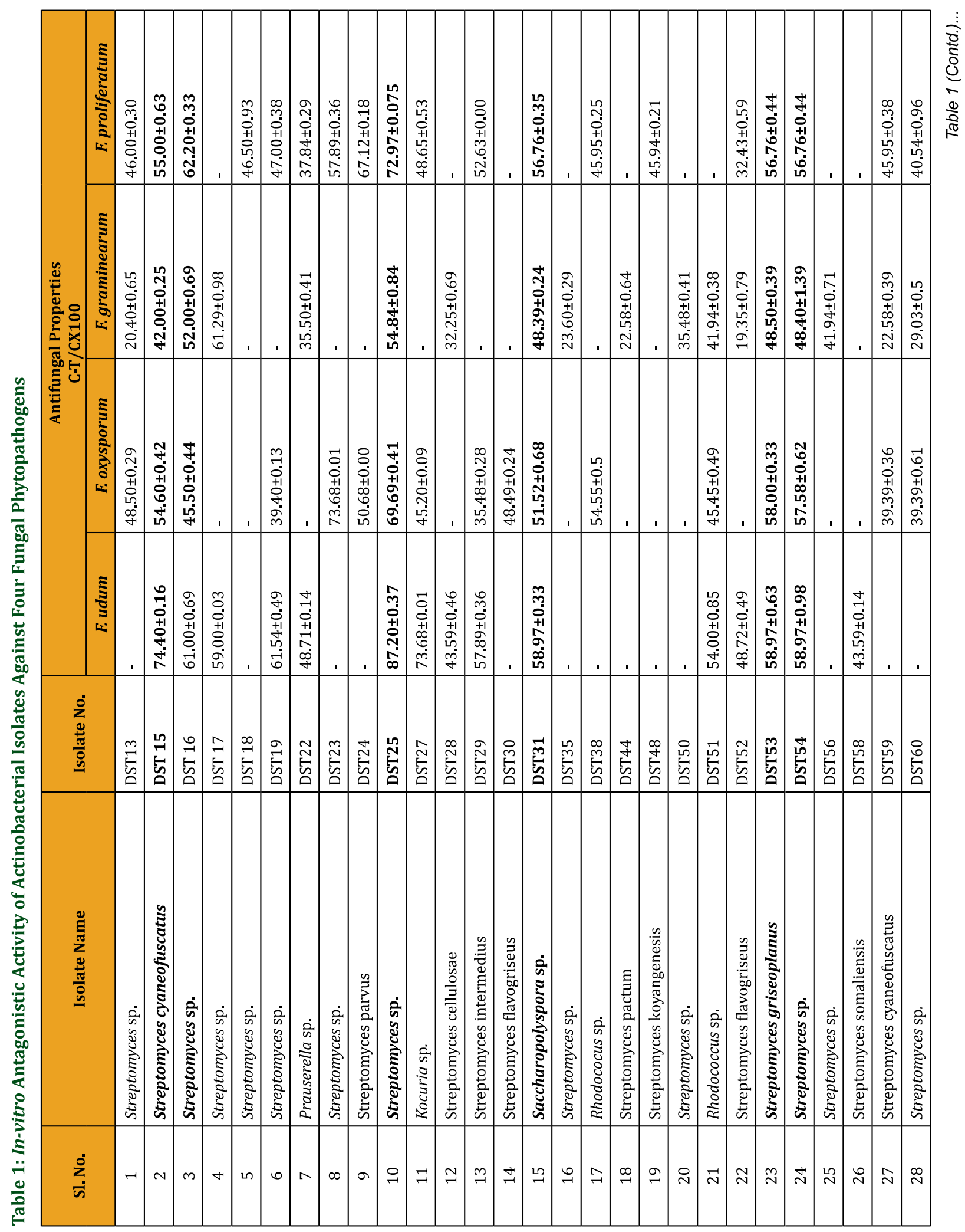




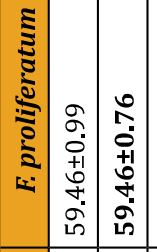

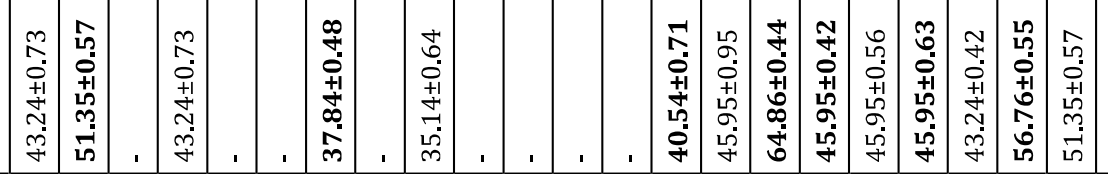

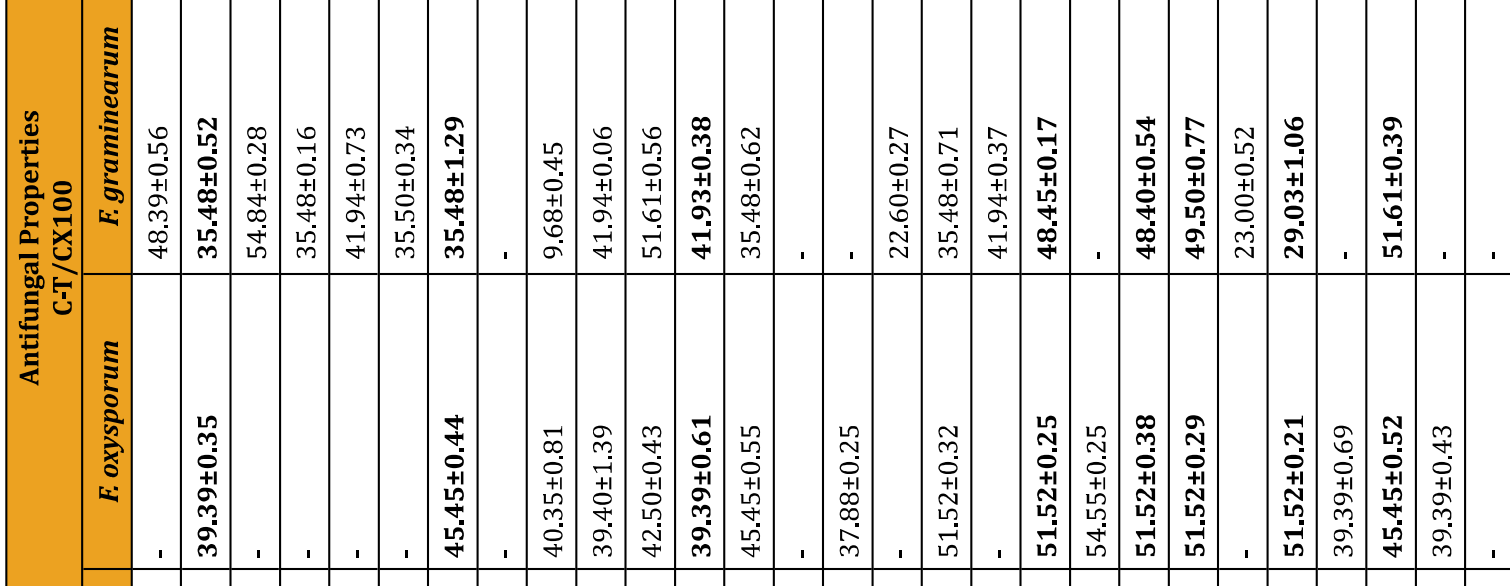

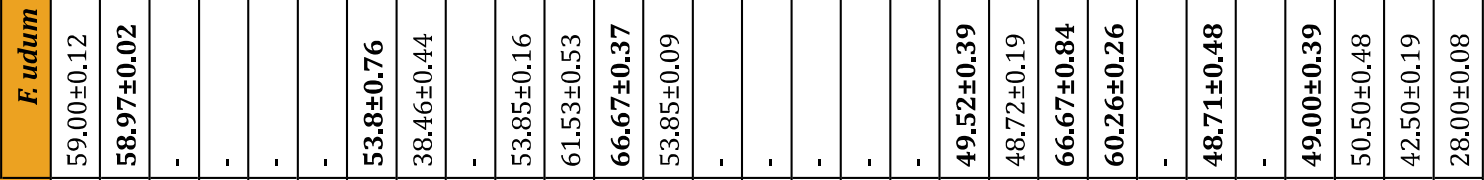

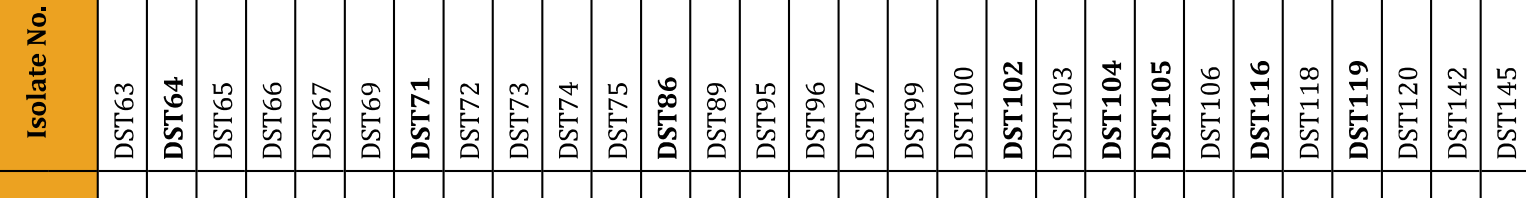

ঠें

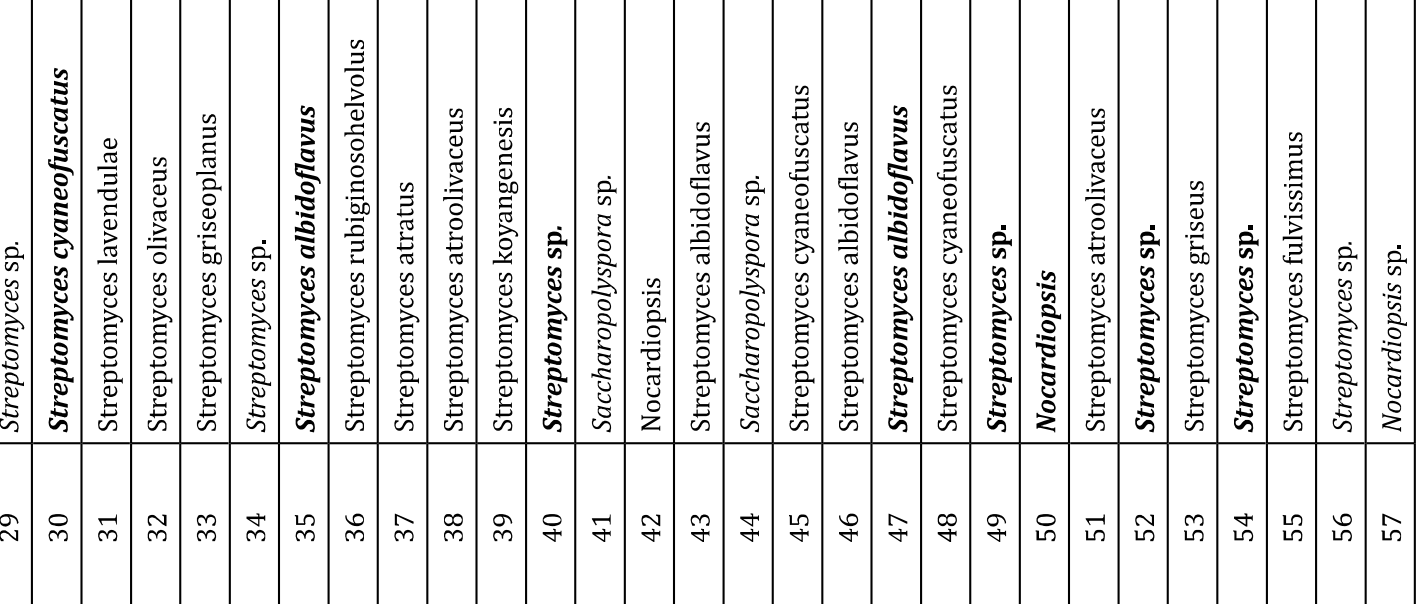




\section{CONCLUSION}

In this study, sixty-eight actinobacteria were isolated from the sediments of three freshwater systems using serial dilution and spread plate technique, where the genus Streptomyces was found to be dominant. They were evaluated for their anti-fungal activity against four Fusarium plant pathogens collected from microbial type culture collection and found that $83.8 \%$ of the isolated organisms showed inhibitory activity against at least one of the tested plant pathogenic fungi and 13 Streptomyces isolates were found to inhibit all the tested pathogens which undoubtedly presented the anti-fungal potential of actinobacteria and might be a good candidate as biocontrol agent especially disease caused by Fusarium pathogens.

\section{REFERENCES}

Bubici G (2018) Streptomyces spp. as biocontrol agents against Fusarium species. CAB Reviews 13, No. 050 doi: 10.1079/ PAVSNNR201813050

Ellaiah P, Adhinarayana K, Adhinarayana K, Saisha V, Madhavi S, Premkumar J (2002) Bioactive actinomycete from Krishna River sediments of Andhra Pradesh. Hindustan Antibiot Bull 44:8-16

Godfray HC, Mason-D'Croz D, \& Robinson S (2016) Food system consequences of a fungal disease epidemic in a major crop. Philosophical transactions of the Royal Society of London. Series B, Biological sciences 371 (1709) 20150467. doi:10.1098/rstb.2015.0467

Goodfellow M, Fiedler HP (2010) Aguide to successful bioprospecting: informed by actinobacterial systematics. Anton Van Leeuwen 98:119-142 doi: 10.1007/s10482-010-9460-2

Goodfellow M, Williams ST (1983) Ecology of actinomycetes. Annu Rev Microbiol 37:189-216

Khamna S, Yokota A, Lumyong S (2008) Actinomycetes isolated from medicinal plant rhizosphere soils: diversity and screening of antifungal compounds, indole-3-acetic acid and siderophore production. World J Microbiol Biotechnol 25:649

Lamprecht SC, Tewoldemedhin YT, Botha WJ, Calitz FJ (2011) Fusarium graminearum species complex associated with maize crowns and roots in the KwaZulu-Natal Province of South Africa. Plant Disease 95:1153-1158. DOI: 10.1094/ PDIS-02-11-0083

Leiva S, Yanez M, Zaror L, Rodrıguez H, Garcıa-Quintana H (2004) Antimicrobial activity of actinomycetes isolated from aquatic environments in Southern Chile. Rev Med Chile 132:151-159

Maldonado LA, Stach JE, Pathom-aree W, Ward AC, Bull AT, Goodfellow M (2005) Diversity of cultivable Actinobacteria in geographically widespread marine sediments. Anton Van Leeuwen 87(1): 8-11

Myers N, Mittermeier RA, Mittermeier CG, da Fonseca GAB, Kent J (2000) Biodiversity hotspots for conservation priorities. Nature 403:853-858
Nafis A, Elhidar N., Oubaha B, Samri SE, Niedermeyer T, Ouhdouch Y,... Barakate M (2018) Screening for Non-polyenic Antifungal Produced by Actinobacteria from Moroccan Habitats: Assessment of Antimycin A19 Production by Streptomyces albidoflavus AS25. International J Mol Cell Med 7(2): 133-145 doi:10.22088/IJMCM.BUMS.7.2.133

Passari AK, Chandra P, Zothanpuia, Mishra VK, Leo VV, Gupta VK, Kumar B, Singh BP (2016) Detection of biosynthetic gene and phytohormone production by endophytic actinobacteria associated with Solanum lycopersicum and their plantgrowth promoting effect. Res Microbiol 167:692-705

Passari AK, Mishra VK, Gupta VK, Yadav MK, Saikia R, Singh BP (2015) In-vitro and in-vivo plant growth promoting activities and DNA fingerprinting of antagonistic endophytic actinobacteria associates with medicinal plants. Plos One doi:10.1371/journal.pone.0139468

Protasov ES, Axenov-Gribanov DV, Rebets YV, Voytsekhovskaya IV, Tokovenko BT, Shatilina ZM, Luzhetskyy AN, Timofeyev MA (2017) The diversity and antibiotic properties of actinobacteria associated with endemic deepwater amphipods of Lake Baikal. Anton van Leeuwen 110:1593

Qi D, Zou L, Zhou D, Chen Y, Gao Z, Feng R, Zhang M, Li K, Xie $\mathrm{J}$ and Wang W (2019) Taxonomy and Broad-Spectrum Antifungal Activity of Streptomyces sp. SCA3-4 Isolated From Rhizosphere Soil of Opuntia stricta. Front Microbiol 10:1390. doi: 10.3389/fmicb.2019.01390

Qi D, Zou L, Zhou D, Chen Y, Gao Z, Feng R, Zhang M, Li K, Xie J, Wang W (2019) Taxonomy and Broad-Spectrum Antifungal Activity of Streptomyces sp. SCA3-4 Isolated From Rhizosphere Soil of Opuntia stricta. Front Microbiol. 10:1390. doi: 10.3389/ fmicb.2019.01390

Rifaat HM (2003) The biodiversity of actinomycetes in the river Nile exhibiting antifungal activity J Mediterr Ecol 4:5-7

Sibanda T, Mabinya LV, Mazomba N, Akinpelu DA, Bernard K, Olaniran AO, Okoh AH (2010) Antibiotic producing potentials of three freshwater actinomycetes isolated from the Eastern Cape Province of South Africa. J Mol Sci 11:2612-2323

Wang X, Zhang M, Gao J, Pu T, Bilal M, Wang Y, Zhang X (2018) Antifungal activity screening of soil actinobacteria isolated from Inner Mongolia, China. Biol Control 127:78-84 https:// doi.org/10.1016/j.biocontrol.2018.07.007

Yuan M, Yu Y, Li HR, Dong N, Zhang XH (2014) Phylogenetic diversity and biological activity of actinobacteria isolated from the Chukchi Shelf marine sediments in the Arctic Ocean. Mar Drugs 12:1281-97

Zotchev SB (2012) Marine actinomycetes as an emerging resource for the drug development pipelines. J Biotechnol 158:168-175

Zothanpuia P, Passari A, Singh BP (2015) Molecular characterization of actinomycetes isolated from Tuichang river and their biosynthetic potential. Sci Vis 15:136

Zothanpuia, Passari AK, Chandra P, Leo VV, Mishra VK, Kumar B \& Singh BP (2018) Bioprospection of actinobacteria derived from freshwater sediments for their potential to produce antimicrobial compounds. Microb Cell Fact 17:68 https:// doi.org/10.1186/s12934-018-0912-0

Zothanpuia, Passari AK, Yadav MK, Singh BP (2018a) In vitro evaluation of antimicrobial activities and antibiotic susceptibility profiling of culturable actinobacteria from freshwater streams. Indian J Exp Biol 56:665-673 